\title{
Validation of an optimized HPLC-UV method for the quantification of formononetin and biochanin A in Trifolium pratense extract
}

\author{
Ju Sung Lee ${ }^{1}$, Leo Adrianne Paje ${ }^{1}$, Min Jeong Kim² , Seung Hee Jang ${ }^{2}$, Jong Tae Kim² and Sanghyun Lee ${ }^{1,3,4^{*}}$
}

\begin{abstract}
Here, two important isoflavones present in Trifolium pratense, formononetin and biochanin A, were analyzed by high performance liquid chromatography coupled with UV (HPLC-UV). These isoflavones are marker compounds with anti-inflammatory, anti-cancer, and anti-oxidant properties, and are also potent phytoestrogens that can be used in hormonal therapies. Till date, no study regarding rapid identification and quantification of T. pratense extract has been conducted. This study developed and validated an optimized method for quantifying formononetin and biochanin A using HPLC-UV. The results showed excellent linearity of the calibration curve $\left(r^{2} \geq 0.999\right)$, and good resolutions of chromatographic peaks were obtained. Other validation parameters such as specificity, accuracy, and precision demonstrated that our method had good reliability and sensitivity. Furthermore, our method for quantifying formononetin and biochanin A in T. pratense extract is convenient.
\end{abstract}

Keywords: Biochanin A, Formononetin, HPLC-UV, Method validation, Trifolium pretense

\section{Introduction}

Plant-derived compounds, which are diverse, have been a subject of interest since the discovery of their crucial role in drug development. Many reports have shown that among the various classes of compounds, flavonoids exhibit different pharmacological activities [1]. Flavonoids are one of the most common components of the human diet. They are generally present in foods in the form of $\mathrm{O}$-glycosides with sugars bound at the $\mathrm{C}-3$ position [2]. These compounds help regulate cellular activity and eliminate free radicals that cause oxidative stress. Studies also reported that flavonoid consumption reduces the risk of cardiovascular diseases and type 2 diabetes [3, 4]. Flavonoids are known to interact with various cellular targets, such as those involved in freeradical scavenging and anti-oxidant activities, and exhibit

\footnotetext{
*Correspondence: slee@cau.ac.kr

${ }^{1}$ Department of Plant Science and Technology, Chung-Ang University,

Anseong 17546, Republic of Korea

Full list of author information is available at the end of the article
}

anti-inflammatory, anti-viral, and anti-cancer properties [5].

Trifolium pratense, also known as red clover, is an herbaceous plant of the Fabaceae family. It is short-lived and varies in size from 20 to $80 \mathrm{~cm}$. It has a deep taproot, due to which it is drought tolerant and positively affects soil structuring. T. pratense is native to Asia minor, China, Europe, and Southern Africa, and North-Central Africa; however, it has also been planted and naturalized in most parts of the world [6,7].

Trifolium pratense has been widely used as a dietary supplement, food, or medicine for treating several ailments such as epilepsy, heart problems, high cholesterol, inflammatory diseases, cancer, sexually transmitted diseases, reproductive system problems, and skin related diseases [8-10]. Its usage is attributed to high contents of estrogenic isoflavones, such as formononetin, biochanin A, daidzein, and genistein. It is considered to be potentially useful as a natural form of hormone replacement therapy for menopause. Therefore, the plant could be utilized as a cheap alternative source for producing original author(s) and the source, provide a link to the Creative Commons licence, and indicate if changes were made. The images or other third party material in this article are included in the article's Creative Commons licence, unless indicated otherwise in a credit line to the material. If material is not included in the article's Creative Commons licence and your intended use is not permitted by statutory regulation or exceeds the permitted use, you will need to obtain permission directly from the copyright holder. To view a copy of this licence, visit http://creativecommons.org/licenses/by/4.0/. 
isoflavone-rich food supplements for females with menopausal issues [10]. Herbalists have employed this plant as an expectorant, blood cleaner, alterative and sedative $[10$, $11]$.

Isoflavones derived from many edible plants have been reported to possess significant estrogenic, anti-oxidant, and tyrosine kinase inhibitory activities [12]. Isoflavones found in T. pratense, such as formononetin and biochanin A have been known to exhibit various pharmacological effects, such as anti-inflammatory, anti-cancer, anti-oxidant, lipid metabolism modulatory, and neuroprotective effects $[13,14]$.

Simultaneous identification of formononetin and biochanin A along with other isoflavones such as genistein and daidzein in $T$. pratense ethanol extract (TPE), has already been reported using HPLC [15]. A study on the contents of isoflavone in TPE indicated that formononetin and biochanin A are the main isoflavone while genistein and daidzein are only present in small amounts [11]. Different methods were utilized to analyze the contents of formononetin and biochanin A in TPE. For example, Xiu et al. analyzed biochanin A and formononetin using HPLC coupled with ELSD and DAD and total biochanins A using HPLC-UV [16]. Despite the research efforts, to date, the rapid identification and quantification of formononetin and biochanin A contents in T. pratense using high performance liquid chromatography (HPLC) has not been achieved. This study aims to establish a convenient technique in quantifying the two marker compounds in TPE by applying our validated and optimized HPLC method.

\section{Materials and methods}

\section{Plant materials and extraction procedure}

The $T$. pratense used in this study was obtained and verified by M. J. Kim from Teazen Co., Ltd., Haenam, Korea. A voucher specimen (No. LEE2017-05) was deposited at the Department of Plant Science and Technology Herbarium, Chung-Ang University, Anseong, Korea. The plant was extracted with ethanol under reflux for $3 \mathrm{~h}$ and repeated 3 times. It was filtered and concentrated in vacuo to obtain the TPE.

\section{Instrumentation, chemicals, and reagents}

All analyses were carried out using an Agilent series 1290 HPLC consisting of a quaternary pump equipped with UV detector (Santa Clara, CA, USA). Samples were separated using an INNO C18 column $(4.6 \mathrm{~mm} \times 250 \mathrm{~mm}$, $5 \mu \mathrm{m})$. HPLC-grade acetonitrile, water and glacial acetic acid were purchased from J.T. Baker (Avantor, Radnor, PA, USA). Formononetin and biochanin A (Fig. 1) were purchased from the Natural Product Institute of Science and Technology (www.nist.re.kr), Anseong, Korea.

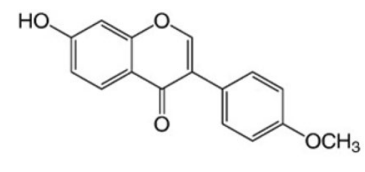

1

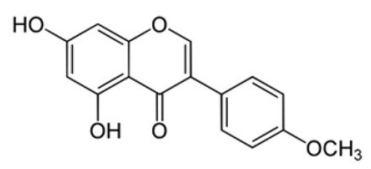

2
Fig. 1 Chemical structures of formononetin (1) and biochanin A (2)

\section{Preparation of samples and standard solutions for HPLC}

The test solution was prepared by dissolving $10.0 \mathrm{mg}$ of TPE in $1 \mathrm{~mL}$ methanol (MeOH). The standard stock solutions were prepared by dissolving $1.0 \mathrm{mg}$ formononetin and biochanin $\mathrm{A}$ in $\mathrm{MeOH}$. The resulting solutions were serially diluted and used to obtain a calibration curve.

\section{HPLC-DAD conditions}

Chromatography was performed using a gradient elution system composed of $1 \%$ acetic acid in water (A) and acetonitrile (B). The gradient elution program started with the mobile phase (A) concentration at $80 \%$, and this concentration was decreased to $63 \%$ after $35 \mathrm{~min}$. The concentration of solvent A was further decreased to $0 \%$ after $45 \mathrm{~min}$ and maintained until $50 \mathrm{~min}$. It increased from 0 to $80 \%$ at $51 \mathrm{~min}$ and was maintained until $61 \mathrm{~min}$. The mobile phase flow rate was $1 \mathrm{~mL} / \mathrm{min}$ and the injection volume was $10 \mu \mathrm{L}$. The UV absorption was measured at $270 \mathrm{~nm}$ and the column temperature was maintained at $30{ }^{\circ} \mathrm{C}$.

\section{Method validation}

The method used to analyze formononetin and biochanin A was validated using different parameters such as specificity, linearity, accuracy, precision, and LOQ. Specificity was evaluated to ensure that the method used for separation was free from interference and analyte impurities. The linearity between the peak area and concentration was analyzed by injecting five concentrations of the standard mixtures three times repeatedly. A calibration curve was plotted using the peak areas measured at $270 \mathrm{~nm}$ on the chromatogram against the known concentration of the standard solutions, and the accuracy of the method was assessed using recovery assays carried out by adding the standard solutions to four different concentrations $(0.015-0.125 \mathrm{mg} / \mathrm{mL})$ of the test solutions. The measurements were obtained five times and the percent recovery was calculated. The precision of the method was investigated in terms of its inter-day and intra-day variation. Intra-day precision was measured by injecting each sample five times in 1 day. Inter-day precision was measured using the same method but was also conducted in a different laboratory to determine the degree of closeness between the values obtained. The LOQ, the lowest analyte amount that can be quantitated with a 
signal-to-noise ratio of 10 , was determined using the values of the standard deviation of the intercept $(\sigma)$ and the slope (S). The following equation was used to calculate the LOQ: $L O Q=10(\sigma / S)$.

\section{Calibration curves}

Different concentrations of formononetin and biochanin A $(0.00781$ to $0.125 \mathrm{mg} / \mathrm{mL})$ were prepared by serially diluting the standard stock solutions. For each compound, the calibration curve, the peak area $(\mathrm{Y})$ was plotted against the concentration $(\mathrm{X}, \mathrm{mg} / \mathrm{mL})$. The analyte concentrations in the samples were calculated using the calibration equation. All values are reported as means $(\mathrm{n}=3) \pm$ standard deviation.

\section{Results and discussion}

Trifolium pratense ethanol extract (TPE) has been extensively investigated in phytochemistry and the results that revealed that formononetin, biochanin $\mathrm{A}$, daidzein and genistein as its main active components. Several studies have analyzed the contents of formononetin and biochanin A in TPE using different methods $[15,16]$. Our study aimed to develop a simple and optimized HPLC method for identifying and quantifying the two marker

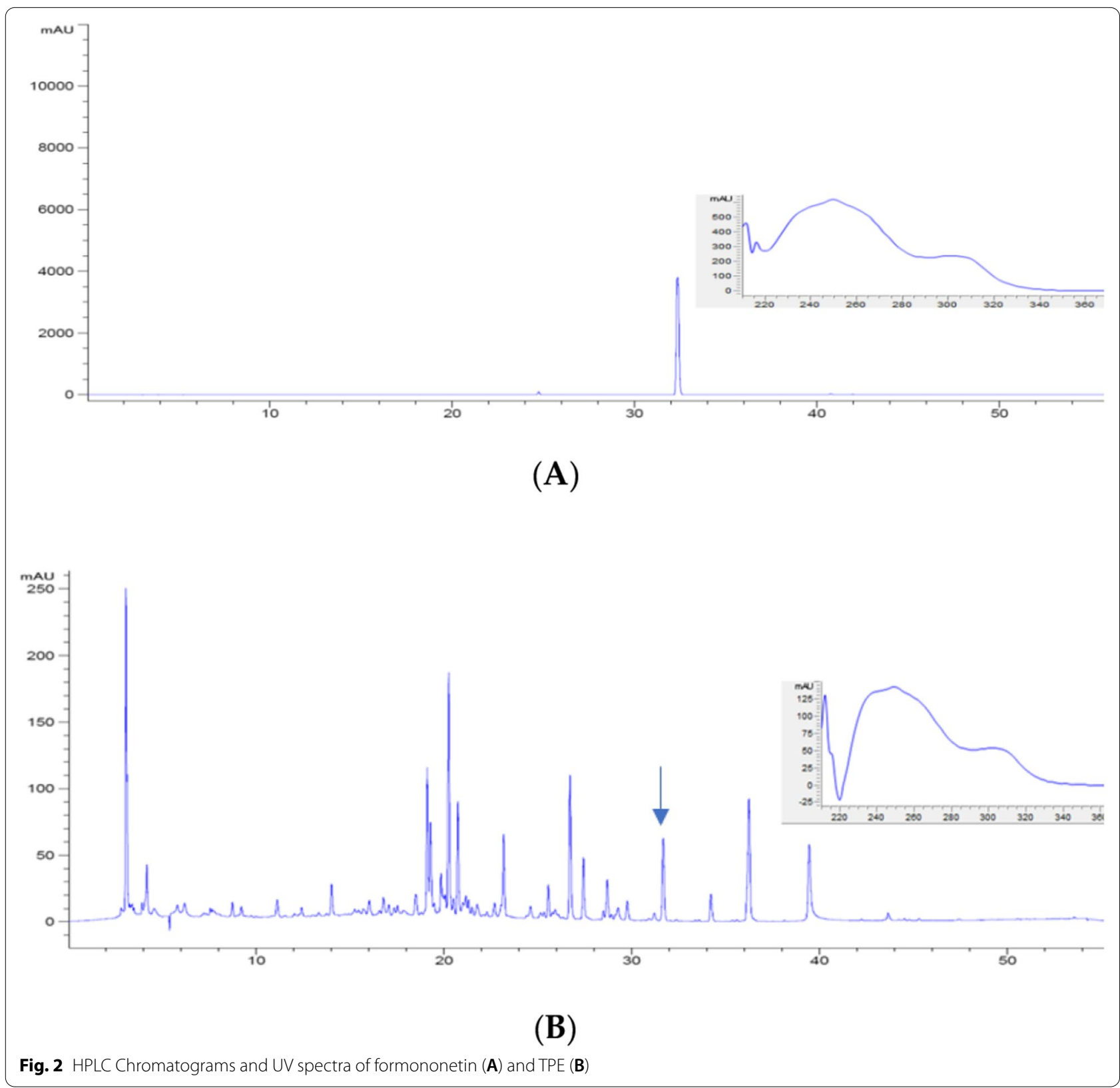


compounds formononetin and biochanin A. The effectiveness of the developed method was validated using different parameters.

The specificity of the method was assessed by analyzing and comparing the chromatograms of the standard compounds and sample solutions. Figures 2 and 3 depict the chromatograms of the standard compounds versus that of TPE. The retention times of standard formononetin and biochanin A compounds were $31.8 \mathrm{~min}$ and $36.3 \mathrm{~min}$, respectively (Figs. $2 \mathrm{~A}$ and $3 \mathrm{~A}$ ). The chromatograms in Figs. $2 \mathrm{~B}$ and $3 \mathrm{~B}$ show an efficient separation between the peaks of formononetin and biochanin A found in TPE. As there were no impurity peaks detected close to their retention times of formononetin and biochanin A, we can say that our method is highly specific. All impurities as well as formononetin and biochanin A were best detected at $270 \mathrm{~nm}$ in a single run.

Accuracy was measured by spiking the test solution with known concentrations of formononetin and biochanin A. The recovery of each substance was determined using the amount found and original amount. The analyses were carried out at least 5 times. As shown in Table 1,

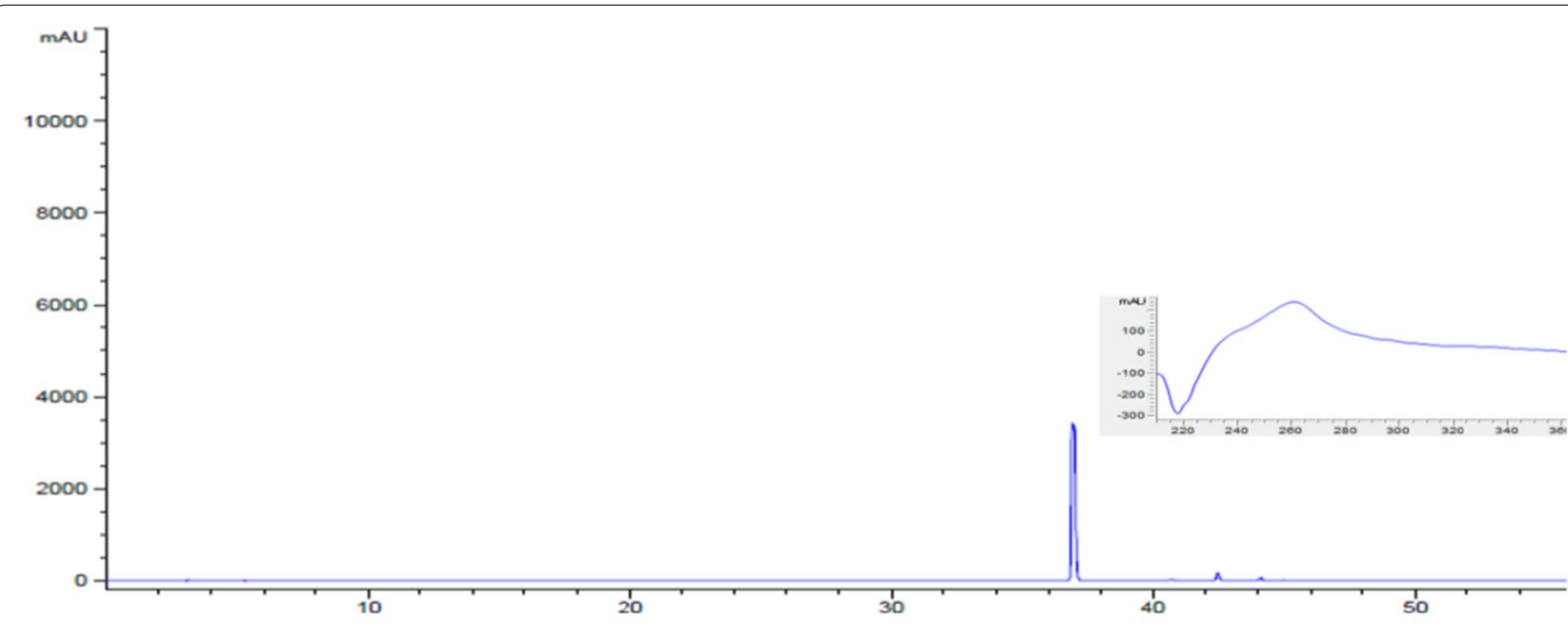

(A)

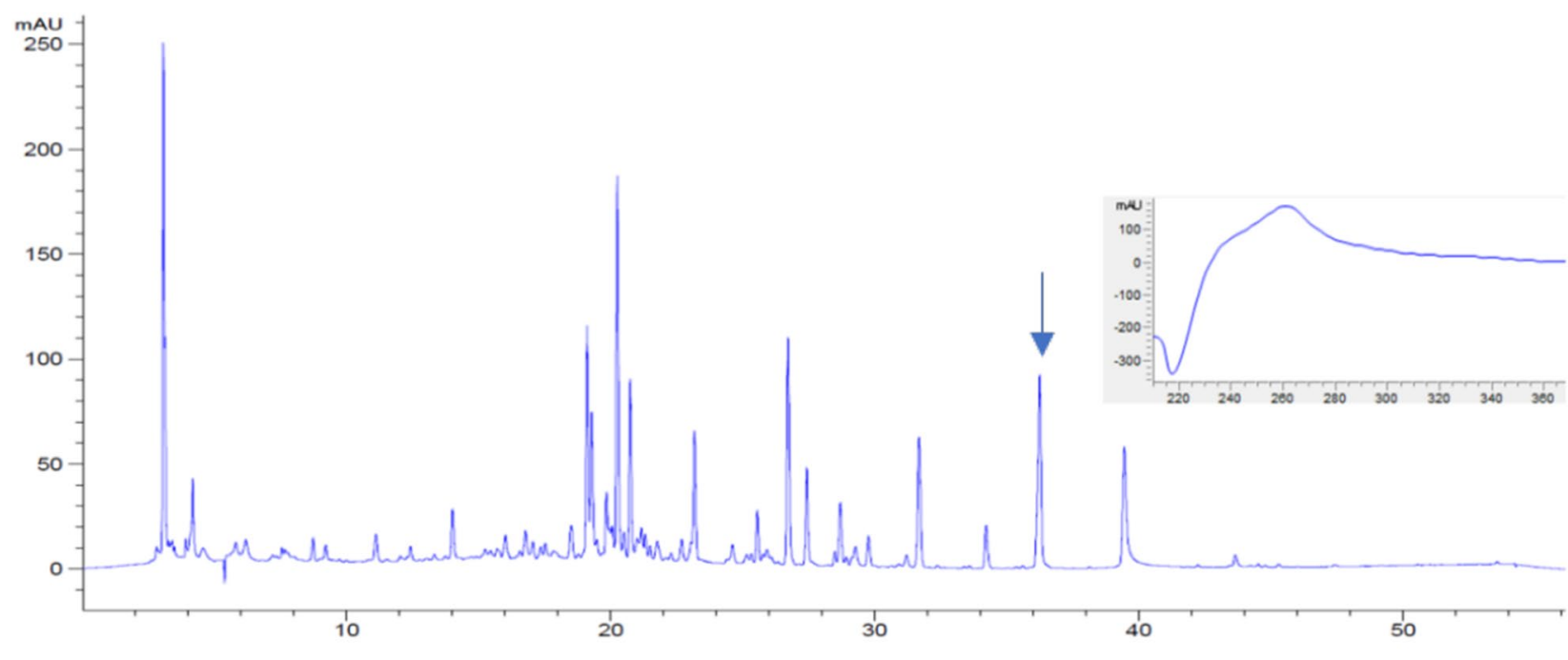

(B)

Fig. 3 HPLC Chromatograms and UV spectra of biochanin A (A) and TPE (B) 
Table 1 Accuracy of formononetin (1) and biochanin A (2) quantification

\begin{tabular}{|c|c|c|c|c|c|c|c|c|}
\hline \multirow[t]{2}{*}{ Compound } & \multirow{2}{*}{$\begin{array}{l}\text { Concentration (mg/ } \\
\mathrm{mL})\end{array}$} & \multicolumn{5}{|c|}{ Measured content $(\mathrm{mg} / \mathrm{g})$} & \multirow{2}{*}{$\begin{array}{l}\text { Average recovery } \\
\text { rate }(\%)\end{array}$} & \multirow{2}{*}{$\begin{array}{l}\text { Overall } \\
\text { recovery } \\
\text { rate }(\%)\end{array}$} \\
\hline & & $1 s t$ & 2nd & 3 rd & 4th & 5 th & & \\
\hline \multirow[t]{4}{*}{1} & 0.125 & 86.86 & 90.30 & 88.68 & 86.75 & 86.62 & 87.84 & 88.38 \\
\hline & 0.0625 & 84.81 & 87.25 & 84.38 & 84.29 & 82.15 & 84.58 & \\
\hline & 0.03125 & 91.52 & 91.73 & 91.45 & 88.80 & 85.73 & 89.85 & \\
\hline & 0.015625 & 91.77 & 95.59 & 92.05 & 90.27 & 90.66 & 91.27 & \\
\hline \multirow[t]{4}{*}{2} & 0.125 & 106.22 & 106.38 & 106.49 & 106.52 & 106.19 & 106.36 & 101.63 \\
\hline & 0.0625 & 98.54 & 99.02 & 98.50 & 100.37 & 100.74 & 99.63 & \\
\hline & 0.03125 & 100.45 & 100.02 & 100.40 & 100.04 & 100.21 & 100.22 & \\
\hline & 0.015625 & 100.18 & 100.52 & 100.92 & 100.69 & 99.11 & 100.28 & \\
\hline
\end{tabular}

Table 2 Intra-day precision for the quantification of formononetin (1) and biochanin A (2)

\begin{tabular}{|c|c|c|c|}
\hline \multirow[t]{2}{*}{ Compound } & \multirow{2}{*}{$\begin{array}{l}\text { Spiked } \\
\text { concentration } \\
(\mathrm{mg} / \mathrm{mL})\end{array}$} & \multicolumn{2}{|l|}{ Intra-day $(n=5)$} \\
\hline & & $\begin{array}{l}\text { Measured } \\
\text { concentration } \\
(\mathrm{mg} / \mathrm{g})\end{array}$ & RSD (\%) \\
\hline \multirow[t]{4}{*}{1} & 15 & 0.87 & 1.02 \\
\hline & 20 & 0.86 & 0.88 \\
\hline & 25 & 0.87 & 0.37 \\
\hline & 30 & 0.86 & 1.03 \\
\hline \multirow[t]{4}{*}{2} & 15 & 1.02 & 0.58 \\
\hline & 20 & 1.00 & 0.68 \\
\hline & 25 & 1.03 & 0.71 \\
\hline & 30 & 1.03 & 1.09 \\
\hline
\end{tabular}

the recovery rates $\%$ for formononetin and biochanin A were $84.58-91.27 \%$ and $99.63-106.36 \%$, respectively. All the obtained values were within the acceptable range, suggesting that our method is highly accurate.

The precision of the method was evaluated using intra- and inter-day precision analyses. Tables 2 and 3 show that the coefficient of variation was $0.37-1.03$ for formononetin and 0.58-1.09 for biochanin A. These values were less than $2 \%$ which indicates that the proposed analytical method was reliable and accurate.

Linearity was evaluated by plotting the peak area against the concentration of the standard compounds expressed in $\mathrm{mg} / \mathrm{mL}$. The correlation coefficient $r^{2}$, and the values of compounds formononetin and biochanin A were 0.999 indicating a strong linear relationship between the peak area and the concentration of the two compounds (Table 4). The LOQ value represents the lowest concentration of an analyzed compound that can be quantified using an instrument or analytical method with acceptable precision and accuracy. As shown in Table 4, the LOQ values of formononetin and biochanin A were 0.016 and $0.019 \mathrm{mg} / \mathrm{mL}$, respectively.
Table 3 Inter-day precision for the quantification of formononetin (1) and biochanin A (2)

\begin{tabular}{|c|c|c|c|}
\hline \multirow[t]{2}{*}{ Compound } & \multirow[t]{2}{*}{ Repetition } & \multicolumn{2}{|c|}{ Inter-day $(n=5)$} \\
\hline & & $\begin{array}{l}\text { Measured } \\
\text { concentration } \\
(\mathrm{mg} / \mathrm{g})\end{array}$ & RSD (\%) \\
\hline \multirow[t]{3}{*}{1} & A & 0.87 & 1.26 \\
\hline & B & 0.87 & 0.96 \\
\hline & C & 0.86 & 1.32 \\
\hline \multirow[t]{3}{*}{2} & A & 1.02 & 1.61 \\
\hline & B & 1.02 & 0.88 \\
\hline & C & 1.02 & 1.11 \\
\hline
\end{tabular}

As the LOQ values for our method fell within acceptable limits, it can be said that our analytical method had good sensitivity.

Determination of the chemical composition of medicinal plants has been a challenge because of the structural diversity of compounds contained by them [17]. Therefore, developing a standardized analytical technique is crucial for identifying compounds present in plant extracts [18]. Validation of an optimized method should conform to the required established protocols. The methods described in previous literatures propose a complex sample preparation and HPLC chromatographic conditions. In this study, we developed a simple yet reliable HPLC-UV analytical method for quantifying two of the most important isoflavones present in TPE, formononetin and biochanin A. Developing an efficient HPLC system is highly in demand for the quality control of pharmaceutical products. Our developed HPLC system has been optimized such that efficient separation and quantification can still be achieved considering that we used a simple method compared to other studies $[15,16]$. These include fast sample preparation, cheaper solvents, optimized mobile phase system, and simpler chromatographic conditions without compromising the results. 
Table 4 Linearity and LOQ for formononetin (1) and biochanin A (2)

\begin{tabular}{|c|c|c|c|c|c|}
\hline Compound & $t_{R}$ & Range (mg/mL) & Calibration equation $^{a}$ & $r^{2 b}$ & $\mathrm{LOQ}(\mathrm{mg} / \mathrm{mL})$ \\
\hline 1 & 31.8 & $0.125-0.00781$ & $Y=5002.2 X+58.6$ & 0.999 & 0.0160 \\
\hline 2 & 36.3 & $0.125-0.00781$ & $Y=7265.0 X+109$ & 0.999 & 0.0190 \\
\hline
\end{tabular}

${ }^{\mathrm{a}} \mathrm{Y}=$ peak area $\mathrm{X}=$ concentration of standard compounds $(\mathrm{mg} / \mathrm{mL})$

${ }^{b} r^{2}=$ correlation coefficient for five calibration data points $(n=5)$

Formononetin and biochanin A are said to be responsible for many biological effects of TPE. For instance, formononetin is a very potent phytoestrogen and has many benefits in hormone therapy. It is well-documented to have anti-tumor, anti-proliferative, growth inhibitory, vasorelaxant, neuro-protective, anti-apoptotic, cardio-protective, mammary gland proliferative, anti-microbial, anti-inflammatory, and anti-oxidant activities [14, 17, 19-22]. Biochanin A plays complex roles in controlling various biological functions by binding to DNA as well as several specific proteins. It also functions as a competitive substrate for some enzymes [23]. It has been shown to have chemopreventive activity against various cancer cell lines and plays a therapeutic role in metabolic and hormonal disorders [24]. It also showed anti-inflammatory and neuroprotective effects $[17,24]$.

Here, formononetin and biochanin A were successfully quantified using HPLC-UV. The excellent results in terms of specificity, accuracy, precision, and linearity of our proposed analytical method were validated using various parameters. This supports the use of our method for accurately identifying and quantifying formononetin and biochanin $\mathrm{A}$ as the marker compounds of TPE.

\section{Acknowledgements}

This study was supported by a grant from Teazen Co., Ltd., Haenam, Korea.

\section{Authors' contributions}

JSL: HPLC analysis and method validation; LAP: data analysis and writing; MJK, SHJ \& JTK: data curation of reference compounds and data processing; $\mathrm{SL}$ : experimental design and writing. All authors read and approved the final manuscript.

\section{Funding}

This study was supported by grants from Teazen Co., Ltd., Republic of Korea.

\section{Availability of data and materials}

Not applicable.

\section{Declarations}

\section{Competing interests}

There is no conflict of interests.

\section{Author details}

${ }^{1}$ Department of Plant Science and Technology, Chung-Ang University, Anseong 17546, Republic of Korea. ${ }^{2}$ Teazen Co., Ltd., Haenam 59017, Republic of Korea. ${ }^{3}$ BET Research Institute, Chung-Ang University, Anseong 17546, Republic of Korea. ${ }^{4}$ Natural Product Institute of Science and Technology, Anseong 17546, Republic of Korea.
Received: 28 June 2021 Accepted: 27 July 2021

Published online: 03 August 2021

\section{References}

1. Ashok A (2011) Pharmacological activities of flavonoids: a review. Int J Pharm Sci Nanotechnol 4:1394-1398

2. Kuhnau J (1976) The flavonoids. A class of semi-essential food components: their role in human nutrition. World Rev Nutr Diet 24:117-191

3. Peterson JJ, Dwyer JT, Jacques PF, McCullough ML (2012) Associations between flavonoids and cardiovascular disease incidence or mortality in European and US populations. Nutr Rev 70:491-508

4. Xu H, Luo J, Huang J, Wen Q (2018) Flavonoids intake and risk of type 2 diabetes mellitus: a meta-analysis of prospective cohort studies. Medicine 97:e0686

5. Chahar MK, Sharma N, Dobhal MP, Joshi YC (2011) Flavonoids: a versatile source of anticancer drugs. Pharmacogn Rev 5:1-12

6. Sabudak T, Guler N (2009) Trifolium L.--a review on its phytochemical and pharmacological profile. Phytother Res 23:439-446

7. Rosso BS, Pagano EM (2005) Evaluation of introduced and naturalized populations of red clover (Trifolium pratense L.) at Pergamino EEA-INTA, Argentina. Genet Res Crop Evolut 52:507-511

8. Lim TK (2014) Trifolium pratense, edible medicinal and non-medicinal plants. Springer 7:925-948

9. Circosta C, Pasquale RD, Palumbo DR, Samperi S, Occhiuto F (2006) Effects of isoflavones from red clover (Trifolium pratense) on skin changes induced by ovariectomy in rats. Phytother Res 20:1096-1099

10. Booth NL, Piersen CE, Banuvar S, Geller SE, Shulman LP, Farnsworth NR (2006) Clinical studies of red clover (Trifolium pratense) dietary supplements in menopause: a literature review. Menopause 13:251-264

11. Krenn L, Unterrieder I, Ruprechter R (2002) Quantification of isoflavones in red clover by high-performance liquid chromatography. J Chroma B 777:123-128

12. Jiang D, Rasul A, Batool R, Sarfraz I, Hussain G, Mateen Tahir M, Qin T, Selamoglu Z, Ali M, Li J, Li X (2019) Potential anticancer properties and mechanisms of action of formononetin. BioMed Res Intl 2019:5854315

13. Yu C, Zhang P, Lou L, Wang Y (2019) Perspectives regarding the role of biochanin A in humans. Front Pharmacol 10:793

14. Tay KC, Tan LT, Chan CK, Hong SL, Chan KG, Yap WH, Pusparajah P, Lee LH, Goh BH (2019) Formononetin: a review of its anticancer potentials and mechanisms. Front Pharmacol 10:820

15. Ramos GP, Dias PMB, Morais CB, Pedro EF, Miguel DA, José A, Zuanazzi $S$ (2008) LC determination of four isoflavone aglycones in red clover (Trifolium pratense L.). Chroma 67:125-129

16. Xiu L, Li B, Li P, Chen Q, Jun Z, Chen F (2010) Simultaneous determination of formononetin, biochanin A, daidzein and genistein in Trifolium pratense (red clover) by HPLC. LCGC Eur 23:406-4011

17. Yu KY, Gao W, Li SZ, Wu W, Li P, Dou LL, Wang YZ, Liu EH (2017) Qualitative and quantitative analysis of chemical constituents in Ardisiae Japonicae Herba. J Sep Sci 40:4347-4356

18. Landim LP, Feitoza GS, Costa JGM (2012) Development and validation of a HPLC method for the quantification of three flavonoids in a crude extract of Dimorphandra gardneriana. Braz J Pharmacogn 23:58-64

19. Kim C, Lee SG, Yang WM, Arfuso F, Um JY, Kumar AP, Bian J, Sethi G, Ahn KS (2018) Formononetin-induced oxidative stress abrogates the activation of STAT3/5 signaling axis and suppresses the tumor growth in multiple myeloma preclinical model. Cancer Lett 431:123-141 
20. Wu JH, Li Q, Wu MY, Guo DJ, Chen HL, Chen SL, Seto SW, Au AL, Poon CC, Leung GP, Lee SM, Kwan YW, Chan SW, (2010) Formononetin, an isoflavone, relaxes rat isolated aorta through endothelium-dependent and endothelium-independent pathways. Nutr Biochem 21:613-620

21. Van DM (2017) Modulation of estrogen synthesis and metabolism by phytoestrogens in vitro and the implications for women's health. Tox Res 6:772-794

22. Suuronen T, Nuutinen T, Huuskonen J, Ojala J, Thornell A, Salminen A (2005) Anti-inflammatory effect of selective estrogen receptor modulators (SERMs) in microglial cells. Inflamm Res 54:194-203

23. Roberts DW, Doerge DR, Churchwell MI, Da Costa GG, Marques MM, Tolleson WH (2004) Inhibition of extrahepatic human cytochromes P450
$1 \mathrm{~A} 1$ and $1 \mathrm{~B} 1$ by metabolism of isoflavones found in Trifolium pratense (red clover). J Agric Food Chem 52:6623-6632

24. Pozzi S, Benedusi V, Maggi A, Vegeto E (2006) Estrogen action in neuroprotection and brain inflammation. Ann N Y Acad Sci 1089:302-323

\section{Publisher's Note}

Springer Nature remains neutral with regard to jurisdictional claims in published maps and institutional affiliations.

\section{Submit your manuscript to a SpringerOpen ${ }^{\circ}$ journal and benefit from:}

- Convenient online submission

- Rigorous peer review

- Open access: articles freely available online

- High visibility within the field

- Retaining the copyright to your article

Submit your next manuscript at $\boldsymbol{\nabla}$ springeropen.com 